\title{
THE ROLE OF KNOWLEDGE IN STUDENT OPINIONS ON GENETICALLY MODIFIED ORGANISMS: AN INTERVENTION STUDY
}

\author{
Jasmien Maes \\ Department of Molecular Biotechnology, Ghent University, Belgium \\ Department of Educational Studies, Ghent University, Belgium \\ Tel: +32 9264 6234, (jasmien.maes@hotmail.com) \\ Godelieve Gheysen \\ Department of Molecular Biotechnology, Ghent University, Belgium \\ Tel: +32 9264 5888, (Godelieve.Gheysen@UGent.be) \\ Martin Valcke \\ Department of Educational Studies, Ghent University, Belgium \\ Tel: +32926486 75, (Martin.Valcke@UGent.be)
}

\begin{abstract}
Biotechnology, which includes genetic modification (GM), is often considered to be a controversial topic. Large amounts of factual information on GM as well as opinions are widely spread, which can affect people's opinions and attitudes towards GM. This paper aims to investigate the nature of students' acquisition of new factual information about genetically modified organisms (GMOs), and how this can be related to how they cope with new factual scientific information and opinions. As such, an intervention study involving 575 sixth year secondary school students was set op. Before, during and after the intervention, students completed a questionnaire measuring their knowledge, perceived risks and benefits, as well as attitudes towards and willingness to eat (WTE) GMOs. The results indicated that acquiring new scientific information increased students' scores related to perceived benefits, and attitudes, while the scores on risk perception decreased. Hearing others' opinion on GMOs (combined pro- and anti-GM) had the opposite effect on the related student scores. In addition, the results suggested that the order in which opinions and factual information are addressed in class does not affect students' attitudes and WTE GMOs as long as both are considered. However, students' perception of risks and benefits differ depending on the order of the intervention phases. Based on these findings and the perceived fluctuations in the studied variables throughout the intervention, it is recommended that both the factual scientific information as well as the controversial GM debate should be addressed in class as early as possible in order to develop clear and balanced scientific conceptions as well as a personal opinion.
\end{abstract}

Keywords: genetically modified food; willingness to eat; intervention; acceptance; biotechnology curriculum; secondary school 


\section{Introduction}

Many studies have been set up to research consumers' acceptance of genetically modified (GM) food and concluded most Europeans hold negative attitudes towards GM crops (Aerni, 2013; Gaskell et al., 2010). Even though genetically modified organisms (GMOs) are considered a controversial topic, the importance of being informed about GMOs is reflected by the inclusion of this biotechnology topic in Flemish school curricula. Providing students with a grounded knowledge base about genetic modification and biotechnology is crucial for making informed decisions and developing related attitudes (Bialek \& Botstein, 2004; Sturgis \& Allum, 2004). This develops their ability to engage in associated debates. Important tasks of the related biotechnology curriculum are (1) tackling misconceptions, (2) triggering critical thinking, (3) dealing with new information and (4) coping with conflicting opinions (Duit \& Treagust, 2003; Jones et al., 2012).

Abundant information is available about biotechnology, varying from factual information based on research to subjective information reflecting opinions (Augoustinos, Crabb, \& Shepherd, 2010; Mcinerney, Bird, \& Nucci, 2004). As to the latter, Thorson (2015) distinguishes between misinformation (false information) and misperceptions (false beliefs). Misperceptions or misconceptions can arise without being misinformed; especially in students who are less knowledgeable about these topics (Allen \& Coole, 2012; Smith \& Knight, 2012). Therefore identifying and tackling misconceptions is a crucial task of education. Teachers have to (re)structure key conceptions when introducing students to specific biotechnological content knowledge (Duit \& Treagust, 2003).

Biotechnology is a fast evolving domain. Many sources give access to information about this topic. For instance, considering the large amount of opinions/information about biotechnology available on the Internet, information selection is a challenging task for students (Saadé, Morin, \& Thomas, 2012). During (science) classes students can learn how to handle this abundance of information. Critical thinking is a key condition to be able to select, judge, analyse and evaluate information to develop a balanced understanding of the topic (Akyüz \& Samsa, 2009; Saadé et al., 2012).

One of the major steps in developing an attitude towards GMO is linked to balancing the risks and benefits associated with GMOs (Frewer et al., 2013; Rollin, Kennedy, \& Wills, 2011). Proponents of GMO will mainly promote associated benefits, while opponents primarily refer to possible risks (Legge Jr \& Durant, 2010; Maeseele, 2011; Maeseele \& Schuurman, 2008). GMOs are in general perceived as risky, next to authors stressing benefits (Pidgeon et al., 2005). However, this perception of risks/benefits can be flawed, since consumers often lack information about GM (Costa-Font \& Mossialos, 2007; Siegrist, Cousin, Kastenholz, \& Wiek, 2007). A distinction should be made between risk assessment building on a scientific evaluation of risks - and risk perception or the subjective assessment of risks (Slovic, 1987). As shown in recent research, being more informed about GM results in lower risk perceptions (Ueland et al., 2012). Trust has also been linked to GM acceptance 
(Marques, Critchley, \& Walshe, 2014; Peters, Lang, Sawicka, \& Hallman, 2007), especially when consumers are less capable to evaluate the benefits and risks of GM food themselves and have to rely on information of other stakeholders (Siegrist, Cousin, Kastenholz, \& Wiek, 2007).

People realizing they are uninformed about GMO risks and benefits are easily encouraged to seek information. Their critical mindset will determine whether misinformation will be linked to misperceptions. But - as shown in recent research - being misinformed about risks and benefits easily translates into holding incorrect factual beliefs, into spreading these beliefs and into being resistant to belief corrections (Nyhan \& Reifler, 2010). In society, being correctly informed is important because it has implications at the political and individual level as it influences decision making (Lewandowsky, Ecker, Seifert, Schwarz, \& Cook, 2012). Holding misconceptions is known to be persistent since people consider these erroneous beliefs as correct (Leiserowitz, Maibach, Roser-Renouf, \& Hmielowski, 2011; Lewandowsky et al., 2012).

Research stresses intuitions and emotions make our mind sensitive to negative information. This seems to be the case in relation to GMOs (Blancke, Van Breusegem, De Jaeger, Braeckman, \& Van Montagu, 2015). The latter can evolve into deep-seated bias if not tackled by education (Blancke et al., 2015). Therefore, students have to develop - as early as possible - a comprehensive picture of the risks and benefits associated with GMOs. Studies with adults found that people's initial beliefs are strong and determine how - at a later stage they deal with or interpret new information (McFadden \& Lusk, 2015).

Schools can offer a supportive environment for informal discussions about GM applications for food production (Mills Shaw, Van Horne, Zhang, \& Boughman, 2008). According to Zohar and Nemet (2002) this involves reasoning about advantages and disadvantages and about risks when proposing alternatives. Biotechnology education presents a fertile ground offering this opportunity.

The main aim of the present study is to determine the nature of students' acquisition of new factual GMO information and how this is related to the way they cope with GMO opinions, including misinformation. To study this relationship, the present research takes into account students' initial knowledge level. All students in the present study had been enrolled in biotechnology classes, implying they should master a basic understanding of biotechnology. The effect of opinions and new factual information on students' perceptions of risks and benefits, and attitudes is investigated, reflecting the effect of information on the Internet and media. This allows researching the status and robustness of their beliefs and attitudes. Though several studies already investigated the relationship between acquiring new (factual) information and people's opinions (Lewandowsky et al., 2012; McFadden \& Lusk, 2015), such studies have hardly been set up involving secondary school students (Gelamdin, Alias, \& Attaran, 2013). 


\section{Research design}

A quasi-experimental cross-over design was set up, building on an instructional intervention to develop a scientific knowledge base, next to the presentation of subjective opinions. For an overview of the study and the nature of the intervention, see Fig. 1. Participants switched research conditions in the middle of the study. In each research condition, classes participated in a complete biotechnology lesson building on two phases: a theoretical phase and a debate phase in which risks and benefits are discussed. The order of these phases was switched in each research condition. In addition, the nature of subjective opinions was manipulated: positive versus negative opinions (see A versus B in Fig. 1). To monitor the differential impact, research instruments were presented during a pre-test, midtest and post-test phase. The latter allowed testing the potential changes in knowledge mastery and the opinions of the students.

\subsection{Research questions}

Building on the available theoretical and empirical base, we present the following research questions:

Research question 1: How stable/amendable are student opinions about GMOs?

Research question 1a: What is the differential impact of being presented first with a particular type of information (factual information versus opinion) on students' development in knowledge of genetics and biotechnology (mid-test scores), considering pre-test differences?

Research question 1b: What is the differential impact of being presented first with a particular type of information (factual information versus opinion) on students' perceived risks, perceived benefits, and attitudes towards GM food (mid-test scores), taking into account pre-test differences?

The next two research questions centre on the role of prior knowledge at the start of the study. Students were subdivided into three groups based on their pre-test knowledge scores.

Research question 2: What is the impact of different pre-test knowledge levels on post-test scores for perceived benefits, perceived risks, attitudes towards GM Food and WTE GMF.

Research question 3: Do changes over time in perceived benefits, perceived risk, attitudes and WTE (pre-test versus post-test) differ depending on initial knowledge levels (i.e. three groups based on pre-test knowledge score)?

After the last intervention phase, all participants had been presented with the scientific information and opinions. A related research question 4 is presented: Is there a significant difference in perceived benefits, perceived risk, attitudes and WTE over time (pre-test versus post-test) in students involved in the two research conditions? 


\subsection{Participants}

In Belgium, secondary education students follow a six-year curriculum (12 -18 year). Students can enrol in three different secondary education tracks: a vocational track (BSO), a technical track (TSO) or a general track (ASO). In view of this study, a sampling framework was developed to select students from the final (sixth) year ASO. This guarantees the topic biotechnology is included as part of participating students' biology curriculum. Survey data from 575 students, enrolled in 29 different schools could be analyzed after data cleaning. More girls (61\%) than boys participated in the study. Age varied between 16 and $20(M=$ $17.46, S D=0.62)$.

\subsection{Procedure and research conditions}

Both the instructional intervention and the data collection were monitored and carried out by trained researchers in the period April-May 2014. Researchers followed a strict protocol. Prior to the study, informed consent was obtained from all students as well as from their teachers. Full school classes were assigned randomly to one of the four experimental conditions (Design 1A, 1B, 2A or 2B). The procedure started with administration of the pretests, comprising of an objective knowledge test and scales measuring students' perceived GMO benefits, perceived GMO risks, attitudes towards GMO, willingness to eat GM crops (WTE) and trust.

Next, all classes were involved in the instructional intervention. All intervention versions were based on videos to guarantee strict control over the content being presented and the instructional format. Participants in design 1A and 1B (see Fig. 1) watched a video lesson on biotechnology covering factual information about traditional breeding and genetic modification. Students in design 2A and $2 \mathrm{~B}$ watched a video in which four stakeholders expressed their opinions about GM food crops. Two versions of this video were available; one starting with two proponents, followed by two opponents. In the second version proponents gave their opinion first.

Next, before students switched research conditions, a mid-test was presented comprising of parallel instruments to the pre-test. This was followed by the next phase of the lesson. Students in design $1 \mathrm{~A}$ and $1 \mathrm{~B}$ watched the opinion video, while the other groups (design 2A and 2B) watched the biotechnology video lesson. After this second part of the intervention, the post-test instruments were administered.

The video lesson took approximately 22 minutes; the opinion video 12 minutes. The time needed to finish the whole procedure, including administration of the instruments was estimated at 85 minutes. To guarantee sufficient time, two consecutive lessons (100 minutes) were blocked in each school to complete the intervention. 

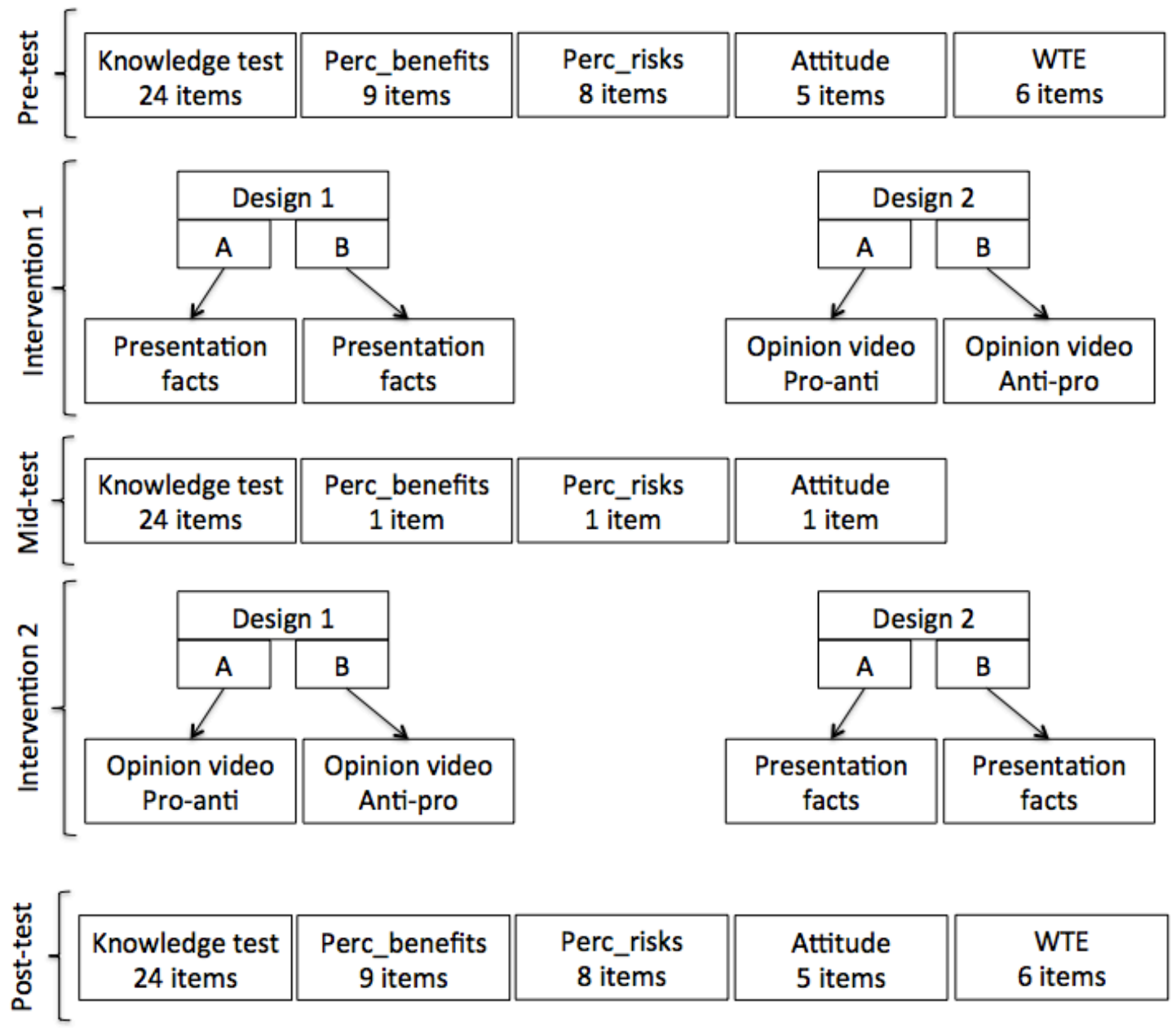

Fig. 1 Overview of the intervention study with the cross-over at the time of presenting the mid-test. The variable trust was not included in the overview as it was only measured during the pre-test.

\subsection{Research instruments}

Students were presented with paper-based research instruments to map their: (1) objective knowledge, (2) perceived benefits, (3) perceived risks, (4) trust in information sources, (5) attitudes towards GM food and (6) WTE GM food.

A bilingual speaker checked translation of some instrument sections from English to Dutch. Content validity of the survey builds on a review by three biotechnology and educational sciences experts. See Appendix for the detailed wording of all items in English.

Objective knowledge test. The items of the knowledge test were adapted from a version developed by Maes et al. (under review). Thirteen true/false statements about biotechnology and genetics, including the commercial status of GMOs were presented, next to 
eleven short answer questions. To prevent guessing, an introductory text indicated that questions could remain unanswered and the option 'I don't know' was added. Objective knowledge was measured with the same statements in the pre- and mid-test phase.

To study the other research variables, items were adapted from Prati, Pietrantoni, and Zani (2012), next to the addition of a limited number of newly developed items. Most scale items were based on a 5-point Likert scale, ranging from 1 (strongly disagree) to 5 (strongly agree).

Perceived Benefits and Risks. Nine scale items were used to study students' perceived benefits related to GM crops. Good scale reliability was observed $(\alpha=.79)$. Eight scale items covered students' perceptions about GM crop (cultivation) risks. An acceptable scale reliability was observed $(\alpha=.74)$. These perceived risks and benefits items were used during the pre- and post-test phase. During the mid-test perceived risks and benefits were evaluated with a single scale item: 'GM crops can offer many benefits'; 'There are many risks associated with GM crops'.

Attitudes. Students' attitudes towards GM crops were evaluated with five scale items. Excellent reliability was observed $(\alpha=.82)$. This scale was used during the pre- and post-test phase. Again, a one scale item 'What is your attitude towards GM crops' was used during the mid-test phase.

Willingness to eat. Six scale items helped measuring students' WTE GM food. Excellent scale-reliability was observed $(\alpha=.83)$. These items were presented during the pre-test and post-test.

Trust. Only in the pre-test version of the instruments, questions were asked concerning trust: questions related to preferred information sources, and questions about the trustworthiness of the sources concerning the food safety when working with GMOs. Respectively nine information sources and six organizations were evaluated.

Secondary school student characteristics: With these items, personal information about gender, age, and class level was collected.

\subsection{Statistical analyses}

SPSS (version 20) was used to calculate descriptive statistics, including means, sum scores, and standard deviations. Cronbach's alphas were calculated to verify scale reliability. To answer research question 1 and 2, ANCOVA's were performed. All assumptions were met except for the homogeneity of regression slopes; the covariate interacted with the independent variable. Green and Salkind (2010) suggest in this case assessing group differences in the dependent variable at levels of the covariate. In practice, the score at which the covariate and 
independent variable interacted was determined and the cross point was used as a new cutoff value to split up the dataset. Next, multiple ANCOVAs could be performed.

To study research question 1, the independent variable builds on the order in which either opinions or knowledge was presented to the students (design 1 versus design 2). Midtest scores on knowledge, perceived benefits, perceived risks and attitudes towards GM food were used as the dependent variable, while the pre-test scores were used as covariates. The use of pretest scores in the statistical analysis enabled the reduction of error variance, making these tests more powerful than designs neglecting pretest data (Dimitrov \& Rumrill, 2003; Stevens, 2012).

For research question 2 and 3, students were divided into three groups, based on their pre-test knowledge scores (Low=12/24 or lower; Medium= 12 to $16 / 24$; High=17/24 or higher). For research question 2 , the same dependent variables and covariates were used as for research question 1, but the prior knowledge level groups defined the factors in the analysis. Mixed between-within subjects ANOVAs were performed to answer research question 3 and 4. This test cannot render which specific groups within each factor significantly differed from each other; it only tells whether there are differences. The categorical independent betweensubjects variable determines the knowledge groups for research question 3 and design (order of the intervention phases) for research question 4; the categorical independent withinsubjects variable is 'time' which represents the pre- and post-test scores on perceived benefits, perceived risks, attitudes towards GM food, or WTE GM food. This test included an additional assumption, homogeneity of inter-correlations, which was evaluated through Mbox statistics when performing the analysis. To answer research question 3 and 4 we mainly tested the interaction effects.

\section{Results}

\subsection{Descriptive statistics}

A summary of the descriptives (pre-test scores) is provided in Table 1. Objective knowledge score was average. Attitudes scores ranged from neutral to rather positive, while students expressed a rather positive intention towards eating GM foods. Students' risk and benefit perceptions were above the mid-point of the scale, though the respondents' perceived benefits to a slightly higher extent. Students indicated university scientists and Flemish Institute of biotechnology as their preferred sources for information about GMOs $(>4 / 5)$. Media were the least preferred source $(<2.5 / 5)$. Further, students placed the highest trust in university scientists when the responsibility of safe handling GM crops is at stake. Seed companies were the least trusted. However, all organizations were evaluated above the midpoint of the scale and therefore considered to be (rather) trustworthy when safety handling is considered. 
Table 1. Means and standard deviation at pre-test, mid-test and post-test measurement occasion

\begin{tabular}{lllllll}
\hline Groups $(n)$ & & $\begin{array}{l}\text { Objective } \\
\text { knowledge } \\
\text { Max }=24\end{array}$ & $\begin{array}{l}\text { Perceived } \\
\text { benefits } \\
\text { Max }=5\end{array}$ & $\begin{array}{l}\text { Perceived } \\
\text { risks } \\
\text { Max }=5\end{array}$ & $\begin{array}{l}\text { Attitudes } \\
\text { Max }=5\end{array}$ & $\begin{array}{l}\text { WTE GMF } \\
\text { Max }=5\end{array}$ \\
\hline Design 1 & Pre-test & $14.81(3.33)$ & $3.25(0.54)$ & $3.19(0.51)$ & $3.43(0.69)$ & $3.57(0.68)$ \\
$(327)$ & Mid-test & $17.71(2.78)$ & $3.83(0.79)$ & $3.07(0.87)$ & $3.50(0.80)$ & $/$ \\
& Post-test & $/$ & $3.20(0.49)$ & $3.27(0.52)$ & $3.38(0.60)$ & $3.50(0.67)$ \\
Design 2 & Pre-test & $15.12(3.43)$ & $3.23(0.49)$ & $3.15(0.53)$ & $3.40(0.70)$ & $3.57(0.73)$ \\
$(248)$ & Mid-test & $15.76(3.37)$ & $3.34(0.91)$ & $3.72(0.78)$ & $2.96(0.86)$ & $/$ \\
& Post-test & $/$ & $3.26(0.50)$ & $3.16(0.53)$ & $3.36(0.63)$ & $3.55(0.69)$ \\
Knowledge & Pre-test & $10.13(1.64)$ & $3.00(0.45)$ & $3.28(0.39)$ & $3.04(0.54)$ & $3.23(0.69)$ \\
group 1 & Mid-test & $13.74(3.33)$ & $3.28(0.65)$ & $3.42(0.71)$ & $2.93(0.70)$ & $/$ \\
$(123)$ & Post-test & $/$ & $3.01(0.39)$ & $3.29(0.43)$ & $3.11(0.51)$ & $3.25(0.66)$ \\
Knowledge & Pre-test & $14.48(1.13)$ & $3.19(0.46)$ & $3.22(0.51)$ & $3.39(0.65)$ & $3.53(0.63)$ \\
group 2 & Mid-test & $16.48(2.34)$ & $3.60(0.88)$ & $3.34(0.89)$ & $3.25(0.83)$ & $/$ \\
(256) & Post-test & $/$ & $3.23(0.44)$ & $3.25(0.50)$ & $3.36(0.56)$ & $3.49(0.60)$ \\
Knowledge & Pre-test & $18.57(1.43)$ & $3.46(0.56)$ & $3.03(0.58)$ & $3.68(0.73)$ & $3.84(0.69)$ \\
group 3 & Mid-test & $19.33(1.90)$ & $3.85(0.93)$ & $3.33(0.98)$ & $3.48(0.94)$ & $/$ \\
(196) & Post-test & $/$ & $3.36(0.56)$ & $3.14(0.60)$ & $3.56(0.68)$ & $3.74(0.72)$ \\
Total & Pre-test & $14.94(3.37)$ & $3.24(0.52)$ & $3.17(0.52)$ & $3.42(0.70)$ & $3.57(0.70)$ \\
(575) & Mid-test & $16.87(3.20)$ & $3.62(0.88)$ & $3.35(0.89)$ & $3.26(0.87)$ & $/$ \\
& Post-test & $/$ & $3.23(0.49)$ & $3.22(0.52)$ & $3.37(0.61)$ & $3.52(0.68)$ \\
\hline
\end{tabular}

Note. WTE GMF: Willingness to eat genetically modified food

\subsection{Research questions}

Research Question 1: How stable/amendable are student opinions about GMOs?

RQ1a. The covariate (pre-test knowledge score) and the independent variable (design) significantly interact when respondents attain a pre-test knowledge score of 15 . Therefore, two separate ANCOVA's were performed, one with students who scored above 15 and one involving students with a score below 15 . In both cases, students who received only additional theoretical and factual information (design 1; see Fig. 1), scored significantly higher on the mid-test knowledge test compared to students who only listen to opinions of actors in the GM-debate (design 2). Pre-knowledge $>15$ : F $(1,258)=80.57, p<0.01$; Pre-knowledge $<15$ : $\mathrm{F}(1,252)=91.91, p<0.01$.

RQ1b. An interaction between pre-test perceived benefits and the independent variable (design) was observed. To deal with this, the data set was split on the base of a pretest perceived benefit score of 3. Students starting in both intervention designs perceived equal benefits before the intervention. After the first intervention phase, students who only watched the factual information video lesson perceived significantly more benefits compared to the group that only watched the opinion video (Pre-test perceived benefits $<3: \mathrm{F}(1,140)=$ $10.07, p<0.01$; Pre-test perceived benefits $>3$ : $\mathrm{F}(1,366)=28.79, p<0.01)$. Further, students' perceptions of risks were comparable in both groups prior to the intervention. Finishing the first phase of the intervention, students in design 1 (facts) perceived fewer risks compared to those in design 2 (opinions), $\mathrm{F}(1,570)=98.30, p<0.01$. The initial attitudes score of students 
was nearly identical in both alternative interventions. But, during mid-test phase students who first watched the video lessons were far more positive compared to those who first watched the opinion video, $\mathrm{F}(1,568)=82.00, \mathrm{p}<0.01$.

Research question 2: What is the impact of different pre-test knowledge levels on post-tests scores for perceived benefits, perceived risks, attitudes towards GM food and WTE GM food.

A significant interaction between perceived benefits and the three pre-test knowledge level groups was detected. Therefore, three separate ANCOVAs were calculated. Firstly, data of students who perceived few benefits (perceived benefit score $<2.4$ ) showed a significant lower post-test benefit score for students with the lowest pre-test knowledge level; $F(2,25)=$ 7.98, $p<0.01$. For the middle and the high perceived benefit groups, no differences in students' post-test scores on perceived benefits could be detected between the three knowledge groups, $\mathrm{F}(2,111)=1.56, p=0.21 ; \mathrm{F}(2,364)=2.29, p=0.102$. No significant differences in scores on perceived risks could be detected between the three knowledge groups, $\mathrm{F}(2,570)=2.29, p=0.10$. Post-test scores for attitudes towards GM food and WTE $\mathrm{GM}$ food did not differ significantly between the three knowledge groups, $\mathrm{F}(2,570)=1.287, p$ $=0.28 ; \mathrm{F}(2,570)=0.44, p=0.65$.

Research question 3: Do the changes over time in perceived benefits, perceived risk, attitudes and WTE (pre-test versus post-test) differ depending on their initial knowledge levels (i.e. three groups based on pre-test knowledge score)?

For perceived benefits, perceived risks and attitudes towards GM food, a mixed within between ANOVA could not be performed because the additional assumption of homogeneity of inter-correlations was not met (significant M-box statistics, $\mathrm{p}<0.001$ ). The ANOVA with WTE GM food could be carried out as M-box statistics were not significant $(p>.05)$. No significant interaction was observed between pre-test knowledge scores and time (pre-and post-test scores), Wilks Lambda $=0.99, F(2,571)=2.40, p>.05$. There was a substantial main effect for time, Wilks Lambda $=0.99, F(1,571)=3.99, p<.05$, partial eta squared $=$ .01 , two groups showed a significant reduction in WTE scores across the two time periods (pre- and post-test scores; see Table 1). The main effect comparing the initial knowledge levels was significant, $F(1,571)=31.76, p<0.01$, partial eta squared $=0.1$.

Research question 4: Are the changes over time in perceived benefits, perceived risks, attitudes and WTE over time (pre-test versus post-test) different for the two designs (i.e. influence of the order of the instructional intervention phases)?

For all ANOVAs the additional assumption of homogeneity of inter-correlations were met (non significant M-box statistics, $\mathrm{p}>0.05$ ).

For perceived benefits, a significant interaction was observed between design and time (pre-and post-test scores), Wilks Lambda $=0.99, F(1,572)=5.07, p<.05$. There was no substantial main effect for time, Wilks Lambda $=1.00, F(1,572)=0.06, p=0.81$, and there 
was no significant change in perceived benefits scores across the two time periods (pre- and post-test scores; see Table 1). The main effect comparing the two designs was not significant, $F(1,572)=0.24, p=0.62$. However, because an interaction effect was observed, the main effects should be interpreted with caution and the plot of time (pre- en post-test scores) and design should be used for further interpretation. This clearly illustrates that perceived benefit scores decreased for students in design 1, while scores increased for students in design 2.

For perceived risks, no significant interaction was detected between design and time (pre-and post-test scores), Wilks Lambda $=0.99, F(1,572)=3.88, p=.05$. However, in combination with the plot this result does not suggest an effect of the order of the intervention of WTE, but does suggest a difference in the magnitude of the effect. There was no substantial main effect for time, Wilks Lambda $=1.00, F(1,572)=2.84, p=.09$; there was no significant change in perceived risks scores across the two time periods (pre- and post-test scores; see Table 1). The main effect comparing the two designs was not significant, $F$ (1, $572)=2.90, p=0.09$.

For attitudes, no significant interaction was observed between design and time (preand post-test scores), Wilks Lambda $=1.00, F(1,572)=0.03, p=.86$. There was no main effect for time, Wilks Lambda $=0.99, F(1,572)=3.56, p=.06$, there was no significant change in attitudes scores across the two time periods (pre- and post-test scores; see Table 1). The main effect comparing the two designs was not significant, $F(1,572)=0.20, p=.66$.

For WTE, no significant interaction was observed between design and time (pre-and post-test scores), Wilks Lambda $=0.99, F(1,572)=1.28, p>.05$. There was a substantial main effect for time, Wilks Lambda $=0.99, F(1,572)=5.17, p<.05$, partial eta squared $=$ .01 ; there was a significant reduction in WTE scores across the two time periods (pre- and post-test scores; see Table 1). The main effect comparing the two designs was not significant, $F(1,572)=0.26, p>0.01$.

\section{Discussion and conclusions}

This study aimed to evaluate students' opinions about GM crops and assessed the impact of new factual information and/or others' opinion on students' knowledge levels, perceived risks and benefits, and attitudes (RQ1). In addition, we investigated whether the initial knowledge level (RQ2 and RQ3) and the order of the intervention phases influenced their opinion (RQ4).

In 2013 a similar survey (pre-test) was conducted with Flemish secondary school students, which allowed optimal comparison with previous research results. In general students passed the knowledge test but displayed a clear lack of awareness of the commercial status of GM products. We were able to confirm the findings of this previous year study (Maes et al,. under review). Moreover other scores (pre-test) were comparable. The students 'neutral' scores on perceived risks and benefits, attitudes, and WTE rather indicated 
indifference. According to Rogers' theory of adoption, being indifferent could imply that people are still in the 'awareness phase' (Everett, 1995). In this early stage, students think about the GM technology without truly reflecting on possible risks or benefits, or having a clear opinion. In order to make informed decisions, more factual scientific knowledge, and knowledge about the societal aspects and the status of GMOs is required. This reintroduces the central importance of school curricula. Furthermore, students' scores related to trust least trust in seed companies when it comes to handling GM crops safely - indicated that students already seem to consider socio-economic issues. This reflects the fact that most consumers tend to distrust multinationals (e.g. march against Monsanto). However, differences in trust between the various information sources were quite limited as all trust scores were above the midpoint of the scale. A possible clarification for this observation is that secondary school students may not feel involved in the GM debate, and are thus yet unable to distinguish several information sources. In reality, in this early adoption phase, it is possible that an overall larger interest in GM related difficulties affects trust in a variety of information sources.

RQ1. The results of the first research question showed that students who only watched the instructional video lesson (design 1) scored higher on the knowledge post-test (mid-test phase) compared to students who first watched the opinion video (design 2). This was to be expected as the factual information in the video lesson contained useful information to complete the knowledge test, whilst the opinion video did not. The students in design 1 had also more positive attitudes, perceived more benefits and less risks compared to students in design 2. These results suggest that additional factual information can lead to higher knowledge scores and a higher level of GMO acceptance. Though this does not reinstall the knowledge deficit hypothesis, knowledge seems to be non-negligible when studying acceptance.

RQ2. The second research question investigated whether the pre-test knowledge level influenced students' scores on the post-test (both intervention phases have been completed). The results indicated that the pre-knowledge levels had no effect on the post-test scores. However, the results reflected one exception: if we only considered students who perceived few benefits (i.e. $<2.3 / 5$ ) before the intervention, students with the lowest pre-test knowledge score perceived significantly fewer benefits than students with average and high pre-test knowledge. This suggests that when students scored below a baseline knowledge level, they perceived fewer benefits. Yet, there is only a weak link between knowledge and perceived benefits, suggesting no major influence of pre-knowledge levels. Furthermore, all students took classes of biotechnology before the intervention, which implies that most students already mastered a basic understanding of biotechnology.

RQ3. When considering the results of the mixed within between ANOVA of WTE to test the impact of pre-knowledge levels on the difference in WTE scores (pre- versus post-test), we observed a significant reduction in WTE (pre- versus post-test) within the two knowledge groups (medium and high knowledge levels). This suggests differences in the effect of the 
initial knowledge levels. Students with higher initial knowledge levels seem to adjust their WTE based on new information while the WTE of students with lower knowledge levels seems to be more resistant to change. Even though we could not perform the ANOVAs for the other variables, the same trend can be perceived based on the descriptive results. Observing this trend emphasizes the importance to teach students how to cope with new (controversial) information. Taking into account the fact that students were only recently introduced to the GMO subject, we could hereby question the 'sustainability' of students' knowledge or the way they (do not) use their knowledge. A study of McFadden and Lusk (2015) showed that the way consumers dealt with new information depended on their prior beliefs on the subject. For example, new information was often re- or misinterpreted to match their prior beliefs with the new information. As a result their posterior beliefs were in line with their prior beliefs despite the new factual information. Therefore, scientific information should be introduced as early as possible so as to prevent students from developing prior beliefs and misconceptions (Allen \& Coole, 2012). Though Nyhan and Reifler (2010) referred to the fact that holding incorrect factual beliefs can lead to resistance to belief correction, we observed unstable and still adaptable beliefs within our student population.

RQ4. No differences could be observed between the changes in pre- and post-test scores on perceived benefits, attitudes and WTE between the two designs. This result, in addition to the results from our first research question, implies that the order in which new factual information and opinions are addressed in class does not have an influence on students' attitudes and WTE GMOs as long as both information types are considered. However, for both the risk and benefit perception we did observe differences in the effect of the order of the interventions. It would seem that students from design 1 (ending with the opinion video) perceived more risks and fewer benefits than those in design 2 (ending with factual information). The factual information within design 2 compensated for the changes in perceived risk and benefit score, as opposed to the opinion video within design 1, even though these students started with the video lesson (factual information). The use of active risk communication by environmental NGOs - who also shared their beliefs on GMOs in the opinion video - is known to be very potent in introducing fear (Maeseele \& Schuurman, 2008), which might explain the higher score on perceived risks. As such, this reinforces the need to guide students when teaching them to balance both risks and benefits as well as opinions with factual scientific knowledge using their critical thinking skills (Akyüz \& Samsa, 2009). For example, when media cover GM, teachers should - together with their students - analyse the presented facts critically and confirm or debunk the statements with scientific evidence.

Finally, this study is not without limitations. Firstly, student classes (existing groups) were assigned randomly to one of the four experimental conditions (Design 1A, 1B, 2A or 2B). It is possible that uncontrolled differences between the classes played a role next to those investigated. However, we tried to minimize the impact of possible differences between groups by applying ANCOVAs including pre-test scores as covariates (Stevens, 2012). Secondly, students received a pre-test, a mid-test and a post-test. The mid-test had to be short 
and variables such as attitudes, perceived risks and benefits - which were measured with several items during the pre- and post-test - were now measured with a single more general item. Changes in test results between the pre- and mid test could therefore not be analysed. Consequently, the first research question only compares the results of the mid-test between different groups while controlling for pre-test scores. Finally, someone's intention does not necessarily match this person's actual behaviour (Mather et al., 2011). As such, it is recommended to reiterate this study including observational measures to investigate actual WTE.

To conclude, the present study emphasizes the role of school curricula in order to develop future citizens that can adopt a balanced position in a changing technological world.

\section{Acknowledgements}

In 2013 and 2014, JM was supported by a PhD scholarship from Ghent University (project COM12/PWM/006 05C00612). In $2015 \mathrm{JM}$ had a PhD scholarship from VIB.

\section{References}

Aerni, P. (2013). Resistance to agricultural biotechnology: The importance of distinguishing between weak and strong public attitudes. Biotechnology Journal, 8(10), 1129-1132.

Akyüz, H. İ., \& Samsa, S. (2009). Critical thinking skills of preservice teachers in the blended learning environment. International Journal of Human Sciences, 6(2), 538-550.

Allen, M., \& Coole, H. (2012). Experimenter confirmation bias and the correction of science misconceptions. Journal of Science Teacher Education, 23(4), 387-405.

Augoustinos, M., Crabb, S., \& Shepherd, R. (2010). Genetically modified food in the news: media representations of the GM debate in the UK. Public Understanding of Science, 19(1), 98-114.

Bialek, W., \& Botstein, D. (2004). Introductory science and mathematics education for 21 st-century biologists. Science, 303(5659), 788-790.

Blancke, S., Van Breusegem, F., De Jaeger, G., Braeckman, J., \& Van Montagu, M. (2015). Fatal attraction: the intuitive appeal of GMO opposition. Trends in plant science.

Costa-Font, J., \& Mossialos, E. (2007). Are perceptions of 'risks' and 'benefits' of genetically modified food (in) dependent? Food Quality and Preference, 18(2), 173-182.

Dimitrov, D. M., \& Rumrill, P. D. (2003). Pretest-posttest designs and measurement of change. Work-andover medical publishers incorporated then IOS Press-, 20(2), 159-165.

Duit, R., \& Treagust, D. F. (2003). Conceptual change: a powerful framework for improving science teaching and learning. International Journal of Science Education, 25(6), 671-688.

Everett, R. (1995). Diffusion of innovations. New York.

Frewer, L. J., van der Lans, I. A., Fischer, A. R., Reinders, M. J., Menozzi, D., Zhang, X., . . Zimmermann, K. L. (2013). Public perceptions of agri-food applications of genetic modification-a systematic review and meta-analysis. Trends in Food Science \& Technology, 30(2), 142-152.

Gaskell, G., Stares, S., Allansdottir, A., Allum, N., Castro, P., Esmer, Y., . . Hampel, J. (2010). Europeans and Biotechnology in 2010 Winds of change?

Gelamdin, R. B., Alias, N., \& Attaran, M. (2013). Students’ And Teachers’ Perspectives On Biotechnology Education: A Review On Publications In Selected Journals. Life Science Journal, 10(1), 1210-1221.

Green, S. B., \& Salkind, N. J. (2010). Using SPSS for Windows and Macintosh: Analyzing and understanding data (6th ed.). Upper Saddle River, New Jersey: Prentice Hall Press.

Jones, A., Buntting, C., Hipkins, R., McKim, A., Conner, L., \& Saunders, K. (2012). Developing students' futures thinking in science education. Research in Science Education, 42(4), 687-708. 
Legge Jr, J. S., \& Durant, R. F. (2010). Public opinion, risk assessment, and biotechnology: lessons from attitudes toward genetically modified foods in the European Union. Review of Policy Research, 27(1), 59-76.

Leiserowitz, A., Maibach, E., Roser-Renouf, C., \& Hmielowski, J. D. (2011). Politics \& global warming: Democrats, republicans, independents, and the Tea Party. Yale University and George Mason University. New Haven, CT: Yale Project on Climate Change Communication.

Lewandowsky, S., Ecker, U. K., Seifert, C. M., Schwarz, N., \& Cook, J. (2012). Misinformation and its correction continued influence and successful debiasing. Psychological Science in the Public Interest, 13(3), 106-131.

Maeseele, P. (2011). On news media and democratic debate: Framing agricultural biotechnology in Northern Belgium. International Communication Gazette, 73(1-2), 83-105.

Maeseele, P., \& Schuurman, D. (2008). Biotechnology and the Popular Press in Northern Belgium A Case Study of Hegemonic Media Discourses and the Interpretive Struggle. Sci Commun, 29(4), 435-471.

Mather, D. W., Knight, J. G., Insch, A., Holdsworth, D. K., Ermen, D. F., \& Breitbarth, T. (2011). Social stigma and consumer benefits: trade-offs in adoption of genetically modified foods. Science communication, 1075547011428183.

McFadden, B. R., \& Lusk, J. L. (2015). Cognitive biases in the assimilation of scientific information on global warming and genetically modified food. Food Policy, 54, 35-43.

Mcinerney, C., Bird, N., \& Nucci, M. (2004). The flow of scientific knowledge from lab to the lay public the case of genetically modified food. Science communication, 26(1), 44-74.

Mills Shaw, K. R., Van Horne, K., Zhang, H., \& Boughman, J. (2008). Essay contest reveals misconceptions of high school students in genetics content. Genetics, 178(3), 1157-1168. doi:10.1534/genetics.107.084194

Nyhan, B., \& Reifler, J. (2010). When corrections fail: The persistence of political misperceptions. Political Behavior, 32(2), 303-330.

Pidgeon, N. F., Poortinga, W., Rowe, G., Horlick-Jones, T., Walls, J., \& O'Riordan, T. (2005). Using surveys in public participation processes for risk decision making: The case of the 2003 British GM nation? Public debate. Risk Analysis, 25(2), 467-479.

Prati, G., Pietrantoni, L., \& Zani, B. (2012). The prediction of intention to consume genetically modified food: Test of an integrated psychosocial model. Food Quality and Preference, 25(2), 163-170.

Rollin, F., Kennedy, J., \& Wills, J. (2011). Consumers and new food technologies. Trends in Food Science \& Technology, 22(2), 99-111.

Saadé, R. G., Morin, D., \& Thomas, J. D. (2012). Critical thinking in E-learning environments. Computers in Human Behavior, 28(5), 1608-1617.

Siegrist, M., Cousin, M.-E., Kastenholz, H., \& Wiek, A. (2007). Public acceptance of nanotechnology foods and food packaging: The influence of affect and trust. Appetite, 49(2), 459-466.

Slovic, P. (1987). Perception of risk. Science, 236(4799), 280-285.

Smith, M. K., \& Knight, J. K. (2012). Using the Genetics Concept Assessment to document persistent conceptual difficulties in undergraduate genetics courses. Genetics, 191(1), 21-32.

Stevens, J. (2012). Applied multivariate statistics for the social sciences: Routledge.

Sturgis, P., \& Allum, N. (2004). Science in society: re-evaluating the deficit model of public attitudes. Public Understanding of Science, 13(1), 55-74.

Thorson, E. (2015). Identifying and correcting policy misperceptions. Retrieved from

Ueland, Ø., Gunnlaugsdottir, H., Holm, F., Kalogeras, N., Leino, O., Luteijn, J., . . Tijhuis, M. (2012). State of the art in benefit-risk analysis: Consumer perception. Food and Chemical Toxicology, 50(1), 67-76.

Zohar, A., \& Nemet, F. (2002). Fostering students' knowledge and argumentation skills through dilemmas in human genetics. Journal of Research in Science Teaching, 39(1), 35-62.

\section{Appendix}

\section{Objective knowledge about GMOs}

\section{True/false Statements}

KOBJ01 If a fish-gene is inserted in a tomato, the tomato will taste like fish (false) 
KOBJ02 A fault in your DNA will be automatically passed to your children (false)

KOBJ03 E-numbers are indicated on the label of several food products. They indicate the presence of flavoring and coloring agents and preservatives. Also GMOs are indicated with an E-number (false)

KOBJ04 Genetic modification of different crop varieties or cattle alters the DNA of the plant or animal (true)

KOBJ05 Half of your DNA originates from your mother, the other half of your father. When your appearance is very similar to your mother, your internal system such as your organs will look more like your father's (false)

KOBJ06 The potato originates from South-America (true)

KOBJ07 Genetically modified corn is commercially cultivated in Europe (true)

KOBJ08 Genetically modified bacteria are used on a large scale for the production of medicines, like insulin (true)

KOBJ09 Plant-DNA can only alter through technical intervention by humans (false)

KOBJ010 The genetically modified potato that was tested in the field trial in Wetteren in 2011 has a bacterial transgene to render it resistant to the potato disease (false)

KOBJ011 We eat DNA daily (true)

KOBJ012 Traditional breeding of different crop varieties or cattle alters the DNA of the plant or animal (true)

KOBJ013 There are no developing countries where genetically modified crops are grown (false)

Note. Each statement could be answered with 'true', 'false' or 'I don't know'.

\section{Short answer questions}

KOBJ14 Where in your body are your genes?

KOBJ15 - 24 Tick the organisms/products that contain DNA.

Humans, animals, plants, bacteria, an apple, water, yeast, an organic apple, a genetically modified apple, sugar

\section{Perceived Benefits}

BENEF01 ${ }^{*} \quad$ The cultivation of genetically modified food will decrease food prices

BENEF02* Genetically modified food will be useful for the fight against hunger in the developing world

BENEF03* The consumption of GM food will be good for society

BENEF04 Genetically modified crops will contribute to a more sustainable agriculture

BENEF05 Genetically modified crops will improve food quality

BENEF06 Cultivation of genetically modified crops will result in lower production costs for farmers

BENEF07 Genetically modified crops will improve public health

BENEF08 Genetically modified crops will increase yield per hectare

BENEF09 Cultivation of genetically modified crops will reduce pesticide use 
*these items were adapted from the questionnaire of Prati et al. (2012).

\section{Perceived risk}

RISK $01^{*} \quad$ Eating genetically modified food is harmful to my health and my family's

RISK02* Cultivating genetically modified crops is harmful to the environment

RISK03* Genetically modified crops threatens the natural order of things

RISK04 Genetically modified organisms will increase the power of large seed multinationals

RISK05 Cultivating genetically modified crops will make organic agriculture impossible

RISK06 Cultivating genetically modified crops will make it hard for farmers to compete

RISK07 Cultivation of genetically modified crops will make local varieties disappear (reduced biodiversity)

RISK08 Genes will spread through cultivation of genetically modified crops and new dangerous plants will arise

*these items were adapted from the questionnaire of Prati et al. (2012).

\section{Attitudes}

AT01* I believe that the use of genetically modified crops is positive

AT02 $^{*} \quad$ I believe that the use of genetically modified crops is wrong (R)

AT03 I believe that the use of genetically modified food should be encouraged

AT04 I believe that the use of genetic modification in food production should not be avoided.

AT05 I believe genetically modified crops are unnecessary (R)

*these items were adapted from the questionnaire of Prati et al. (2012).

\section{Willingness to eat}

$\mathrm{IC}^{*}{ }^{*} \quad$ I intend to eat genetically modified crops

$\mathrm{IC} 02^{*} \quad$ I intend to consume genetically modified crops in the future

IC03 $^{*} \quad$ I would eat genetically modified crops if it was cheaper than ordinary food

IC04 I would eat genetically modified crops if its production would cause less damage to the environment compared to the production of conventional crops (less pesticides)

IC05 I would eat genetically modified crops if they were healthier compared to conventional crops

IC06 I would eat genetically modified crops if poor farmers would be better paid for it

*these items were adapted from the questionnaire of Prati et al. (2012).

\section{Trust}

INFO 01-09 When I'm looking for information about genetically modified crops I would like to receive information from 
(1) environmental NGOs like Greenpeace, (2) GM industry, (3) scientists working for university, (4) Flemish Institute for Biotechnology, (5) teachers, (6) medical doctors, (7) scientists working for multinationals, (8) Belgian government, (9) media.

Every information source was evaluated on a 5-point Likert scale, ranging from 1 (strongly disagree) to 5 (strongly agree)

RESP 01-06 I trust following organizations/companies/people that they are aware of their responsibility on food safety when handling GM crops.

(1) scientists working for university, (2) scientists working for GM industry, (3) pharmaceutical companies, (4) seed companies, (5) food processing companies, (6) farmers

Every information source was evaluated on a 5-point Likert scale, ranging from 1 (strongly disagree) to 5 (strongly agree). 